\title{
O polêmico espaço da argumentação inscrito no filme Entre os muros da escola
}

\author{
Jonathan Raphael Bertassi da Silva* \\ Soraya Maria Romano Pacífico" \\ Lucília Maria Abrahão e Sousa*** \\ Maria Beatriz Ribeiro Prandi ${ }^{* * *+*}$
}

\section{Resumo}

Neste trabalho, busca-se compreender o imaginário sobre argumentação e autoria na instituição escolar conforme inscrito em efeitos de sentido no filme Entre os muros da escola (2008), de Laurent Cantet, fundamentando-se nos pressupostos teóricos da Análise do Discurso (AD) francesa, de matriz pecheutiana. Por meio dos conceitos específicos da $\mathrm{AD}$ para a análise dos processos discursivos verbais e não verbais de acordo com suas respectivas materialidades significantes, mas, sobretudo, dos conceitos de argumentação e autoria também conforme tratados especificamente pelo arcabouço teórico da $\mathrm{AD}$, foram mobilizados recortes do filme que evidenciam a escola como um aparelho ideológico de Estado calcado num discurso autoritário, mas também um espaço no qual pode irromper o novo, a ruptura com o já-lá, o acontecimento discursivo, enfim, a abertura para o discurso polêmico tal qual descrito por Orlandi (2003).

Palavras-chave: Argumentação. Autoria. Cinema. Discurso. Imaginário.
Graduado em Ciências da Informação e da Documentação na Faculdade de Filosofia, Ciências e Letras de Ribeirão Preto da Universidade de São Paulo (FFCLRP/ USP). Mestre e doutor em Psicologia pela FFCLRP/ USP. E-mail: cid_sem_registro@yahoo.com.br

** Graduada em Letras na Faculdade de Educação São Luís. Mestre em Linguística e Língua Portuguesa pela Faculdade de Ciências e Letras Júlio de Mesquita Filho (Unesp). Doutora em Ciências pelo Programa de Pós-Graduação em Psicologia da FFCLRP/USP. Cumpriu estágio de pós-doutoramento na Faculdade de Ciências e Letras da Unesp. Desde 2003 é docente com dedicação exclusiva na USP. E-mail:smrpacifico@ ffclrp.usp.br

*** Graduada em Letras no Centro Universitário Barão de Mauá de Ribeirão Preto. Especialista em Análise do Discurso. Doutora direto em Psicologia pela Faculdade de Filosofia, Ciências e Letras de Ribeirão Preto da USP. Livre docente em Ciência da Informação na mesma instituição. Desde janeiro de 2003, é docente (MS3) com dedicação exclusiva na USP. Coordena o grupo de pesquisa Discurso e Memória: movimentos do sujeito. E-mail: luciliamasousa@gmail.com

***** Bacharela em Biblioteconomia, Ciências da Informação e da Documentação na FFCLRP/USP. Especialista em Artes Visuais, Intermeios e Educação no Instituto de Artes da Universidade de Campinas. Mestra em Ciências pelo Programa de Pós-Graduação em Educação da FFCLRP/USP. Doutoranda em Ciências no Programa de Pós-Graduação em Psicologia, Processos Culturais e Subjetivação da mesma instituição. Atualmente é pesquisadora do Laboratório Discursivo: sujeito, rede eletrônica e sentidos em movimentos (E-L@DIS) na FFCLRP/USP. E-mail: bia.prandi@usp.br

Data de submissão: set. 2017 - Data de aceite: jan. 2018 http://dx.doi.org/10.5335/rdes.v14i1.7401 


\section{Introdução}

Mobilizando o referencial teórico-metodológico da Análise do Discurso (doravante $\mathrm{AD}$ ) pecheutiana, este trabalho propõe uma investigação acerca da autoria e da argumentação no espaço escolar conforme o imaginário evidenciado no discurso cinematográfico do longa-metragem Entre os muros da escola (2008), dirigido pelo cineasta Laurent Cantet e vencedor da Palma de Ouro no festival de cinema em Cannes. Para tanto, parte-se do discurso artístico (DA), segundo conceitualização de Neckel (2004), a fim de avançar no terreno da $\mathrm{AD}$ não verbal em sua materialidade significante, sem perder de vista a imbricação do verbal com o imagético.

A representação da escola e sua relação com a argumentação na sétima arte são muito extensas, gerando um sem fim de filmes que inscrevem efeitos de sentido sobre disciplina, autoria, confrontos com o professor e outras questões no seio da instituição escolar. Devido à vastidão de filmografia disponível, optou-se especificamente por recortes de Entre os muros da escola. Fica especialmente relevante a abordagem desse tema, se visto como Aparelho Ideológico de Estado (AIE), conforme conceitualizado pelo filósofo francês Louis Althusser (1980), um dos autores que serviu de fonte para Michel Pêcheux definir, nos anos sessenta e setenta do século XX, a marca (indissociável) da ideologia da/na linguagem como pesquisada pela Análise do Discurso francesa.

\section{Fundamentação teórica e metodologia}

Tem-se como arcabouço teórico e metodológico a $\mathrm{AD}$ de filiação francesa, sobretudo os postulados teorizados por Michel Pêcheux e pelos autores que compartilha(va)m com ele a preocupação em observar o discurso como processo imbricado numa rede de múltiplas significações possíveis, ao invés de se limitarem a perceber o sentido como um produto pronto e acabado a ser extraído pelos leitores. Esse olhar, característico do analista de discurso, não pode restringir-se à "mensagem" do filme, visto que, pela $\mathrm{AD}$, se desloca a observação do produto para o processo.

O discurso não é entendido como um conjunto de textos, mas como efeitos de sentido entre interlocutores. Como consideraram-se as condições de produção do sentido e as formações discursivas (FD) e ideológicas, a materialidade significante nos modos de produção dos sentidos também é passível de análise. A opacidade da linguagem não é característica apenas do verbal, portanto o discurso artístico pode ser compreendido em seu funcionamento nos processos verbal e não verbal.

Não se perspectiva, no entanto, o sujeito como sendo cartesiano, ele não é dono nem origem de seu discurso, apesar de julgar-se como tal. Contudo, é entendido como posição e constitui-se 
afetado pelos esquecimentos $n^{\circ} 1$ e $n^{\circ}$ 2 (PÊCHEUX, 2014), respectivamente, ele não se dá conta de que fala a partir de dada formação discursiva, tampouco das palavras parafrásticas que poderiam ocupar um mesmo lugar em seus dizeres (embora com outros efeitos de sentido), mas que foram deixadas de lado ao longo da interlocução, bem como tem o sujeito a certeza de uma correspondência direta entre seu pensamento e a linguagem.

[...] a questão do discurso na forma-sujeito: uma vez que não existe prática sem sujeito (e, em particular, prática discursiva sem sujeito), uma vez que os "indivíduos-agentes [...] agem sempre na forma de sujeitos enquanto sujeitos" (ALTHUSSER, 1978, p. 67), a questão da prática discursiva levará necessariamente à questão do efeito do complexo das formações discursivas na forma-sujeito. Não se trata de dizer, porém, que uma prática (discursiva ou não) seja a prática de sujeitos (no sentido de atos, ações, atividades de um sujeito [...]), mas sim de constatar que todo sujeito é constitutivamente colocado como autor e responsável por seus atos (por suas "condutas" e por suas "palavras") em cada prática em que se inscrever (PÊCHEUX, 2014, p. 197, grifo do autor).

Isso posto, compreende-se, com a $\mathrm{AD}$, que nenhum dizer é "adâmico" ou brota no momento da fala do sujeito, dado que o contexto socio-histórico o determina e constitui sua legitimidade de sentidos. Os dizeres são construídos com base em outros já postos em jogo, reverberando a memória discursiva dada por palavras que circularam antes em outros contextos sociais. É o que formula Pêcheux nos seguintes termos:
[...] é necessariamente um espaço móvel de divisões, de disjunções, de deslocamentos e de retomadas, de conflitos de regularização [...]. Um espaço de desdobramentos, réplicas, polêmicas e contra-discursos [...]. $\mathrm{E} o$ fato de que exista assim o outro interno em toda memória é, ao meu ver, a marca do real histórico como remissão necessária ao outro exterior, quer dizer, ao real histórico como causa do fato de que nenhuma memória pode ser um frasco sem exterior (1999b, p. 56).

Tomar a palavra em movimento, partindo dos sentidos já ditos, implica considerar que a escola não é um significante que surge no momento da enunciação, muito no avesso disso, essa palavra só pode ser interpretada, lida e tomada a sério se a considerarmos em sua historicidade. E elas - escola e sua historicidade - constituem-se a partir de vários sentidos: escola pode ser o lugar não tão somente de estudar e brincar, mas também de deixar o filho na escola para poder trabalhar, de socializar e fazer amigos, de desenvolver metodologias novas, de sustentar uma volta aos tempos do grupo escolar, de ganhar dinheiro como investidor, de esperar a aposentadoria, de cortar gastos do orçamento público, de fazer campanha política, de dar ou não aula; enfim, vários sentidos circulam sobre essa palavra, e o sujeito, da posição que ocupa, toma-os para enunciar como se eles fossem seus, muitas vezes, apagando a historicidade que os constitui.

Para a AD, realizar a leitura com base na perspectiva da univocidade absoluta, seguindo o mito da transparência da linguagem, é, conforme indica Ferreira 
(2003), ilusório e ingênuo. Não há sentidos literais, categóricos, passíveis de uma decodificação unívoca pelo sujeito-leitor, como se esse processo estivesse desvinculado do contexto socio-histórico. Muito pelo contrário: a $\mathrm{AD}$ vem justamente mostrar como, tanto na função de autor quanto na de leitor, o sujeito inscreve significados eivados de historicidade. A ideologia se reflete, portanto, no processo da leitura, o qual tende sempre a ser plural e múltiplo. Fundada nos anos 1960 por Michel Pêcheux e Jean Dubois, a AD é uma disciplina criada a partir dos postulados de outros três domínios disciplinares: a Linguística, o Marxismo e a Psicanálise. Dubois era lexicólogo, portanto, tinha embasamento voltado à Linguística. Pêcheux, por sua vez, filósofo, envolvido nos debates da época com Marxismo, Psicanálise e Epistemologia (MUSSALIM, 2000).

A noção de discurso para a $A D$ é diferente daquela recorrente no senso comum. Se neste a palavra é empregada para se referir, especificamente, ao uso da retórica, a pronunciamentos de políticos ou a qualquer outro que prime pela eloquência em eventos sociais de relevância, na perspectiva teórica que adotamos, o discurso - objeto de investigação científica da disciplina - é entendido como "efeitos de sentido entre interlocutores" (PÊCHEUX, 2014), rompendo, portanto, com a definição do senso comum. Os sentidos das palavras não são transparentes nem literais em relação aos significantes (embora o sujeito tenha essa ilusão), não existem em si mesmos, mas são determinados pelas posições ocupadas no processo socio-histórico, o palco da reprodução das palavras no qual o sujeito está intrinsecamente ligado para fazer circular seus dizeres.

Onde está a linguagem está a ideologia. Há confrontos de sentidos, a significação não é imóvel e está no processo de interação locutor-receptor, no confronto de interesses sociais. Portanto, dizer não é apenas informar, nem comunicar, nem inculcar, é também reconhecer pelo afrontamento ideológico. Tomar a palavra é um ato dentro das relações de um grupo social (ORLANDI, 2003, p. 34).

Ideologia aqui é um conceito capilar na teoria discursiva que não está relacionado à ocultação da verdade e da mentira ou à filiação política no sentido estrito e, frequentemente, repetido no senso comum. Trata-se de um processo constitutivo da linguagem, ou melhor, de uma condição para o sujeito inscrever-se na linguagem, que diz respeito ao modo de naturalização de certo sentido como evidente para representar o mundo. Dito de outro modo, o sujeito, estando em dada posição, toma os sentidos como evidentes e óbvios para representá-lo ali, considerando que o seu dizer não poderia ser dito de outro modo, fazendo parecer e acreditando que as suas palavras correspondem ao seu pensamento e mantêm com o mundo uma relação termo a termo.

Desse processo de captura ideológica e de interpelação não é possível escapar. Para ser sujeito e para inscrever-se na língua, é preciso entrar nesse jogo e dizer, a partir dele: 
[...] a interpelação do indivíduo em sujeito do seu discurso se realiza pela identificação do sujeito com a FD que o domina, identificação na qual o sentido é produzido como evidência pelo sujeito e, simultaneamente, o sujeito é produzido como causa de si mesmo (PÊCHEUX, 1969, p. 261).

Nesse sentido, o conceito de condições de produção é fundamental para compreender os discursos em movimento, posto que o dito constitui-se afetado pela moldura do socio-histórico nos termos que Orlandi pontua:

O contexto histórico-social, a situação, os interlocutores - isto a que chamamos tecnicamente de condições de produção - constituem a instância verbal produzida, ou seja, o discurso (2003, p. 83).

Assim, as condições de produção formam a conjuntura socio-histórica que orienta determinadas representações imaginárias, as quais irrompem numa formação discursiva. Somente levando as condições de produção em conta é que podemos entender o discurso como processo de permanente tensão entre a estrutura e o acontecimento (PECCHEUX, 2014).

A Análise do Discurso de Michel Pêcheux indica ser fundamental compreender a linguagem em seu funcionamento na injunção com a história, ou seja, tomar o modo como os processos de produção de sentidos funcionam ideologicamente em seus bordejamentos definidos pela conjuntura sócio-histórica [sic]. Nesses termos, o que está na língua configura-se a partir da posição que o sujeito ocupa na formação social e o modo como se posiciona em relação ao poder (SOUSA; GARCIA, 2017, p. 13).

No âmbito da $\mathrm{AD}$, salienta-se que o não verbal muitas vezes tem sido renegado a um espaço marginalizado como objeto empírico de análise; por ser assim, defende-se a relevância teórica de pesquisas como esta. Pelo estudo formal da imagem, não se consideram seus usos sociais, historicamente determinados, como ocorre na mídia. Limita-se, pois, a uma descrição formal da imagem sem considerar sua materialidade como dimensão discursiva (SOUZA, 1998).

Visa-se, neste trabalho, a interpretar os sentidos sobre o não verbal e sua relação com o discurso verbal. Para tanto, utilizam-se os conceitos de teóricos da $\mathrm{AD}$ que mobilizam esta reflexão. De fato, o não verbal é com frequência marginalizado nas teorias que têm as linguagens como objeto de estudo. $\mathrm{Na} \mathrm{AD}$, vem sendo trabalhada essa dominância do verbal sobre o não verbal, sobretudo na mídia. Um dos trabalhos mais representativos é o de Orlandi (1995), que encara essa suposta dominância do verbal como vinculada ao "mito da informação" recorrente na imprensa, mito este que trabalha o signo sobre a ilusão referencial, de literalidade, buscando o que ele/ela "quer dizer", ação típica do viés conteudístico, tão combatida pela AD. Nesse sentido, a autora descontrói o imaginário de que uma imagem vale mais do que mil palavras, apontando que cada materialidade com a qual o analista se depara reclama um gesto de tratamento e interpretação, visto que é singular e inscreve efeitos de sentido a seu modo.

Concorda-se com Neckel (2004) sobre a arte ser condenada a interferir e transformar, o que ocorre pela ruptura 
e pela contestação, pois o lugar da arte, tanto quanto o contexto socio-histórico, é cambiante e não sedimentado. A imagem como operadora da memória social, para Pêcheux (1999a), comporta um programa de leitura em seu interior, mas inscrito discursivamente em outro lugar, o que faz dela algo comparável à recitação de um mito. Ao mover o estudo da imagem para o referencial do discurso, entendemos o texto imagético, segundo Souza (1998), com suas marcas de heterogeneidade, tal qual o silêncio, o implícito e a ironia. No entanto, essas marcas não podem ser pensadas como vozes, sob risco de reduzir a análise do não verbal às categorias típicas do verbal.

\section{Autoria e argumentação no AIE escolar e no cinema}

Partindo do conceito de Aparelhos Ideológicos de Estado (AIEs) de Althusser (1980), podemos compreender de que maneira o discurso sobre vigilância e punição se faz presente em filmes que inscrevem sentidos sobre o AIE (a polícia e o exército), mas também, como essa mesma região de sentidos é resgatada no interdiscurso sobre diversos AIEs, tais quais família, escola, igreja, manicômio, entre outros. Althusser (1980) defende que, iniciando na modernidade, o par família-escola passa a ser dominante entre os AIEs, substituindo o par família-igreja do feudalismo.
O par família-escola está particularmente bem representado no longa-metragem inaugural da nouvelle vague francesa, Os Incompreendidos (1959), de François Truffaut. A história narra as desventuras do garoto Antoine, negligenciado, por um lado, pela família imersa em discussões conjugais e oprimido, por outro, pelas regras da instituição escolar. O espaço que o garoto encontra para (se) discursivizar a resistência é a arte, faltando às aulas e se distanciando da família para ir ao cinema e procurar livros (até comete pequenos furtos para consegui-los), a ponto de dormir em uma gráfica. Enquanto os pais culpam um ao outro pelo comportamento indisciplinado de Antoine, sobretudo na escola, terminam por colocá-lo numa instituição de regras bem mais rígidas que a escola tradicional, tentando ao mesmo tempo discipliná-lo e puni-lo. Por sua vez, o filme Se... (1968), de Lindsay Anderson, lançado quase uma década depois, na Inglaterra, versa sobre a rebeldia adolescente no AIE escolar, sem dúvida influenciado pelos movimentos de Maio de 68 e afins, que sacudiram a Europa naquele contexto e, afinal, são também reflexos do período socio-histórico e ideológico em que Foucault e Althusser redigiram seus escritos.

Para sustentar as análises que serão apresentadas, recorre-se à tipologia discursiva proposta por Orlandi (2003). Ao tratar das tipologias do discurso - o autoritário, o polêmico e o lúdico -, Orlandi assim os define: 
O discurso lúdico é aquele em que seu objeto se mantém presente enquanto tal (enquanto objeto, enquanto coisa) e os interlocutores se expõem a essa presença, resultando disso o que chamaríamos de polissemia aberta (o exagero é o non sense). O discurso polêmico mantém a presença do seu objeto, sendo que os participantes não se expõem, mas ao contrário procuram dominar seu referente, dando-lhe uma direção, indicando perspectivas particularizantes pelas quais se $o$ olha e se o diz, o que resulta na polissemia controlada (o exagero é a injuria). O discurso autoritário o referente está ausente, oculta pelo dizer, não há realmente interlocutores, mas um agente exclusivo, o que resulta na polissemia contida (o exagero é a ordem no sentido em que se diz "isso é uma ordem", em que o sujeito passa a instrumento de comando) (2003, p. 15, grifos nossos).

O discurso autoritário, partindo dessa conceituação de Orlandi (2003), faz-se presente não apenas na prisão e na escola, conforme descreve de maneira categórica Michel Foucault (1987), mas também em outros AIEs, com a resistência surgindo na argumentação a partir de rupturas e silenciamentos de personagens que se opõem à formação discursiva dominante. No próprio cinema (o AIE cultural), por exemplo, apesar de entendermos o discurso artístico enquanto pertencente à tipologia lúdica, há resistências ao novo: basta notar como, antes do já citado filme de estreia de Truffaut, poucos cineastas se aventuravam a produzir sentidos sobre a escola como instituição opressora do sujeito-aluno. Isso para nós é indício de que a escola nem sempre é tema da arte, pois é pouco discursivizada pelo cinema, pela pintura e pela música. Apenas em fotografia de Roberto Doisneau (1912-1994) é possível vê-la vivificada pela presença de crianças em momentos diversos que paralisam efeitos de alegria (sempre nas brincadeiras) e de tédio (no cumprimento de tarefas). Tal silenciamento leva a questionar de que modo tal instituição é um aparelho ideológico, um espaço discursivo de produção de sentidos, e como se dá sua representação no cinema, tendo chamado a atenção a maneira que Entre os muros da escola instala efeitos de sentido da escola na qualidade de instituição que, se por um lado é autoritária por excelência, por outro também é (ou deveria ser?) o lugar para o confronto - da ousadia, da assunção da autoria do sujeito-aluno perante a figura pretensamente imponente do professor - e para a emergência do novo, do acontecimento.

Pacífico (2016) reflete sobre o modo como a argumentação pode, ou não, ser uma prática discursiva na instituição escolar, considerando que nesse lugar o discurso pedagógico sustenta-se em uma relação desigual de poder, logo, de direitos. Segundo a autora:

Com efeito, há uma luta de classes, no contexto escolar; logo, dominação e resistência constituem a relação entre os sujeitos-escolares, que podem identificar-se ("bom aluno"), ou não ("mau aluno"), com a determinação exterior; daí, a argumentação pode, ou não, instalar-se. Mas quando as relações de poder entram em jogo é preciso ressaltar que a tomada de posição para argumentar, como a entendo, não depende apenas da identificação do sujeito com dados sentidos, mas sim, depende de ele ter o direito, ou não, de argumentar (PACÍFICO, 2016, p. 194).

Nesse sentido, a autora critica o fato de os sujeitos-alunos não serem autorizados a disputar sentidos com o professor, 
com as vozes de autoridade que ecoam "entre os muros da escola", vozes que, para ela, negam ao sujeito o direito à polissemia, à interpretação e à autoria. Para Pacífico (2016), há uma relação estreita entre argumentação e autoria, pois para argumentar é fundamental que o sujeito assuma a responsabilidade pelo dizer, que trabalhe o interdiscurso no intradiscurso, ou seja, que ele tenha acesso aos sentidos já construídos socio-historicamente e, com base nisso, tenha o direito de produzir o seu fio discursivo-argumentativo. Essa relação de direito ou de interdição à produção de sentidos pode e deve ser analisada tanto no verbal quanto no não verbal.

Seguindo a noção de DA, Neckel (2004) entende os processos discursivos como fatores determinantes para a construção dos sentidos e não o produto que daí resulta. Para a autora:

Parece-nos que por ser constituído de processos discursivos "livres" e abertos, como o polissêmico e o não-verbal, não há como "rotulá-lo" de polêmico, autoritário ou lúdico. Ao nosso ver, o discurso artístico, por intermédio da materialidade e das práticas discursivas que o constituem, poderá apenas apontar uma predominância do lúdico, sendo que a análise interessa-se antes pelo processo do que pelo produto.

O processo criativo, tratado enquanto processo discursivo, é carregado de interfaces históricas, sociais e ideológicas, e o artista se insere em uma determinada formação discursiva para produzir seu dizer que tanto pode ser da ordem do verbal ou do não verbal (NECKEL, 2004, p. 55).

De tal modo, mesmo sendo fundado pelo não verbal, o DA é atravessado pelo verbal, que é subvertido pela não linearidade, de modo que tanto verbal quanto não verbal imbricam-se para constituir a polissemia do DA. Nesse, o processo, afetado pelas condições de produção, determina o produto. $\mathrm{O}$ artista aparece aí como sujeito do discurso, interpelado por rupturas e pela falha, mas condicionado à função da autoria, que é muito disciplinada socialmente. É o confronto de formações discursivas que confere abertura e fechamento aos processos verbal e não verbal, produzindo efeitos de sentido a partir das condições de produção que são histórico-ideológicas. Assim sendo, o efeito-autor, tal como enunciado por Gallo (2001), parece a priori mais evidente no DA pela ludicidade de sua tipologia discursiva. Vale lembrar que

um tipo de discurso é uma configuração de traços formais associados a um efeito de sentido caracterizando a atitude do locutor face a seu discurso, através desse face ao destinatário (ORLANDI, 2003, p. 28).

Assim, de acordo com Orlandi (2003), o discurso pedagógico (DP) seria um discurso neutro que transmite informação, puramente cognitivo, informacional. Contudo, o DP é um discurso circular, que está atrelado a

[...] um dizer institucionalizado, sobre as coisas, que se garante, garantindo a instituição em que se origina e para a qual tende: a escola. $\mathrm{O}$ fato de estar vinculado à escola, a uma instituição, portanto, faz do DP aquilo que ele é, e o mostra (revela) em sua função (ORLANDI, 2003, p. 28).

Dessa maneira, para a autora, tal discurso funciona de modo a não produzir abertura para novos sentidos, cristalizando um efeito parafrástico de sentidos tidos como únicos, a serem re- 
petidos como verdade, ou seja, o discurso pedagógico funciona como um discurso do tipo autoritário.

Ora, sabemos pela teoria do discurso de Pêcheux que a contradição, o equívoco e a ambiguidade atravessam os processos de constituição da linguagem e os sujeitos; nessa direção, entendemos que o discurso pedagógico sustenta-se no movimento de fazer manter a presença da monofonia, da paráfrase e da repetição de uma única voz. No entanto, sabemos, também, que esse processo conta com furos e espaços vazados que passam a ser movediços e tensos com conflitos e disputas, ou seja, ele funciona fazendo ranger a contradição que se dá a ver quando a presença da voz dos sujeitos-alunos irrompe, produzindo deslocamentos e desestabilizações nesse processo. Mas não apenas ela: muitos materiais didáticos apresentam poetas, textos literomusicais e links de consulta em que a polissemia é marcada e convoca os sujeitos a produzir outros sentidos, o que nos permite inferir que tal processo de disputa pelos sentidos é sempre (in)tenso.

Sujeito à falha, ao jogo, ao acaso, e também à regra, ao saber, à necessidade. Assim o homem (se) significa. Se o sentido e o sujeito poderiam ser os mesmos, no entanto, escorregam, derivam para outros sentidos, para outras posições. A deriva, o deslize é o efeito metafórico, a transferência, a palavra que fala com outras. Entre o jogo e a regra, a necessidade e o acaso, no confronto do mundo e da linguagem, entre o sedimentado e o a se realizar, na experiência e na história, na relação tensa do simbólico com o real e o imaginário, o sujeito e o sentido se repetem e se deslocam (ORLANDI, 1999, p. 53).
Sob um olhar mais atento, porém, percebemos o furo nessa constatação: como pontuamos, não necessariamente o DA, lúdico, é sempre um espaço no qual a autoria acontece (vide a sucessão de franquias e remakes que cada vez mais toma conta do cinema comercial estadunidense, condicionando a maior parte do cinema daquele país a paráfrases dos sentidos "velhos"), mas também nem sempre o discurso pedagógico, autoritário, é o da repetição da "velha" ordem discursiva e dos silenciamentos, até então, tomados pelo sujeito, em especial o sujeito-aluno, como natural. Pela inscrição de sujeitos-alunos e, às vezes, de sujeitos-professores, marcados por posições discursivas de insatisfação, questionamento e poesia, temos no processo discursivo na sala de aula a evidente contradição entre a paráfrase e a polissemia:

A paráfrase convive em tensão constante com o outro processo: a polissemia. A polissemia desloca o "mesmo" e aponta para a ruptura, para a criatividade: presença da relação homem-mundo, intromissão da prática na/da linguagem, conflito entre o produto, o institucionalizado, e o que tem de se instituir. [...] A tensão constante com o que poderia ser (ORLANDI, 2003, p. 137).

Tal confronto, garantindo a argumentação na prática escolar, pode vir, inclusive, a recorrer a outras materialidades diferentes da escrita, seja à oralidade, seja ao não verbal, representando lugares de polemização à memória da legitimação associada à escrita, como podemos apreender nos recortes de Entre os muros da escola que analisaremos a seguir. 


\section{Os muros do discurso autoritário: análise de alguns recortes do filme}

Na coleta das sequências discursivas para a pesquisa, uma vez consultado todo o filme na busca por arquivo sobre argumentação e autoria na escola, trabalhou-se com os conceitos de segmento e recorte, conforme enunciados por Souza (2001), com base em Orlandi (1984). O segmento está sugerido a priori na montagem do filme, enquanto a noção de recorte é instituída pelo analista, o que favorece a relação silêncio e imagem não sugerida pela estrutura do filme. Orlandi (1984) alega que o recorte, diferentemente do segmento, é um pedaço, um fragmento, que não organiza os dizeres do outro de modo linear e cronológico. $\mathrm{O}$ espaço do texto nunca é fechado em si, tem relação com o contexto e com outros textos, mas o recorte e o segmento lidam de formas diversas com essa "seleção", com a ideia de começo, meio e fim que pode ser mais (no caso do segmento) ou menos (no caso do recorte) "fechada".

Neste trabalho, decidiu-se analisar dois recortes do filme de Laurent Cantet, nos quais o confronto entre o sujeito-aluno e a autoridade do sujeito-professor acontece por meio de uma redação exigida pelo segundo.

Contudo, antes da análise, é interessante destacar que o filme é baseado no livro de François Bégaudeau (2003), que, além de escrever o roteiro, interpreta $o$ personagem principal do filme (o pro- fessor). Além disso, a narrativa é uma combinação de ficção com documentário, uma vez que o autor/roteirista/ator escreveu Entre Ler Murs a partir da sua experiência em um colégio da zona de educação prioritária de Paris como professor de francês. Não por menos, os atores que interpretam os alunos também o eram na vida real, e não atores profissionais, e muitos dos argumentos utilizados pelos sujeitos-alunos foram espontâneos (CORRÊA, 2010).

$\mathrm{O}$ primeiro recorte traz a argumentação dos alunos e consequentes réplicas do professor, quando este sugere uma tarefa para a classe. No segundo, mais de dez minutos depois, temos novos desdobramentos narrativos (e discursivos), quando os alunos apresentam a realização da referida tarefa ao mestre. Na altura dos 30 minutos e 35 segundos até os 33 minutos, o professor Morin (François Bégaudeau) sugere aos alunos a realização de um autorretrato escrito a ser apresentado na aula do dia seguinte, o que poderia receber uma decodificação acrítica do sujeito-aluno; porém, aos poucos, gera um crescente mal-estar na classe graças à má recepção da tarefa.

Percebe-se que Morin não exige o autorretrato de uma maneira qualquer. Antes de solicitar a redação, pede a leitura de um trecho de O Diário de Anne Frank (1974) a uma das alunas e, só então, após alegar que com a leitura do livro "descobrem coisas sobre Anne Frank", solicita aos alunos que redijam um autor- 
retrato tal qual aquele que acabaram de ouvir, revelando "coisas que exprimam sentimentos, emoções, que me contem histórias, que me permita conhecê-los melhor" (Figura 1). Duas interpretações, com efeitos de sentido convergentes no discurso audiovisual, mas inscritas de maneiras diferentes, são possíveis para essa sequência discursiva. Uma delas se dá no nível diegético do filme - ou seja, "dentro" da história contada, na narrativa ficcional narrada -, a outra se inscreve no DA do filme, na decupagem que faz circular certos sentidos em detrimento de outros, ao tecer um fio narrativo pela imbricação imagética/verbal. Ambas as narrativas se fundem para fazer circular a opressão e a resistência, simultâneas, do sujeito-aluno.

Figura 1 - Menção a Anne Frank fora da diegese: discurso autoritário ignorado pelos alunos

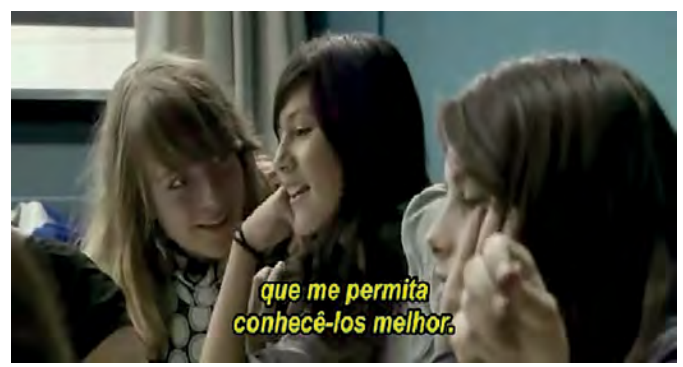

Fonte: Entre os muros da escola (2008).

No âmbito da narrativa ficcional (diegético), o fato de o diretor ter selecionado $O$ Diário de Anne Frank para apresentar o funcionamento do autorretrato e a subsequente tarefa tem fortes implicações ideológicas. O texto versa sobre uma garota judia, cuja perseguição da família pelos soldados nazistas foi contada no diário. Como a $\mathrm{AD}$ refuta qualquer análise da linguagem que não considere a ideologia e o inconsciente, é quase imediato, para nós, o paralelo entre a história (real) narrada pela garota durante a Segunda Guerra Mundial e a situação vivida pelo sujeito-aluno. O sujeito-professor, mesmo não tendo feito essa "escolha" de modo consciente, antecipa no jogo das FD a relação de força entre a posição sujeito-professor e a sujeito-aluno: espera-se que este se identifique na pele do perseguido, do acuado; o opressor (professor) antecipa que é assim que o oprimido (aluno) discursiviza(-se) no autorretrato que virá, no qual os possíveis embates ideológicos materializados na língua serão "fiscalizados" pela repressão do professor. De fato, o sujeito-aluno reage como que na defensiva nos minutos seguintes. No nível fora da diegese, Entre os muros da escola vai construindo, ao mesmo tempo em que coloca o professor nesse lugar que se antecipa como "nazista", o escape dos alunos. A edição dos planos sugere, enquanto ouve-se a breve descrição das expectativas de Morin, o desinteresse de quase todos os alunos na fala do professor, que se lançam em conversas paralelas, deitam na carteira quase dormindo. Ou seja, mesmo que - ao menos nesse momento do filme - ainda não exista a argumentação e a autoria, encontram-se indícios da resistência dos alunos. 
Dos 31 minutos até o fim deste recorte, os sujeitos-alunos inscrevem uma série de formulações que os coloca numa posição de estranhamento e antecipada "incapacidade" de ocupar o papel da autoria. Os motivos alegados por eles são variados, supõem que: suas vidas não são interessantes o suficiente, não têm idade para contar histórias pertinentes, seus sentimentos são privados e não devem ser escritos, não passaram pelas mesmas emoções que Anne Frank. Quase nos 32 minutos do filme (Figura 2), uma das alunas, finalmente, começa um pequeno embate ao alegar que a vida do professor é diferente, simplesmente por ser ele "o professor".

Figura 2 - É "diferente" porque "é professor": a não naturalização da autoria para o sujeito-aluno

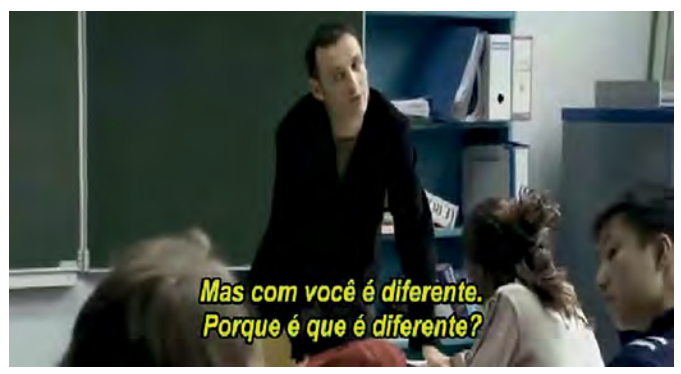

Fonte: Entre os muros da escola (2008).

Cabe ressalvar um detalhe. Morin é professor de língua francesa na escola do filme, isto é, como se fosse professor de língua portuguesa no Brasil. Isso significa uma memória institucionalizada do sujeito que ocupa esse lugar não só como aquele a quem é sabida a assunção da autoria "porque é professor", mas também como "fiscal gramático", memória da noção de autor como aquele que domina a norma culta da língua. Grigoletto e Agustini (2009) trabalharam com a $\mathrm{AD}$ de redações de alunos mais ou menos da mesma idade daqueles retratados no filme e relataram como se dá a memória do poder do professor da língua nativa, e como os alunos antecipam a interlocução com esse sujeito:

Para complicar a questão do apagamento da singularidade nos textos escolares, há, para esses textos, um leitor marcado, o professor de Língua Portuguesa, ao qual é projetada uma imagem - histórica, ideológica e socialmente construída - de uma figura que exerce um poder de alguém que detém o saber sobre o suposto autor - o estudante. Assim, a avaliação do processo de autoria, na maioria das vezes, se resume a apontamentos de deslizes coesivos e gramaticais das normas da língua padrão, desconsiderando os efeitos de sentido produzidos pelo texto. Ainteração leitor/autor se torna, então, automática e atende a uma única exigência: inserir os alunos em um modelo de texto, com uma escrita padrão. $O$ controle do discurso ultrapassa aqui as fronteiras da forma, da escrita e passa a determinar o sentido produzido também (GRIGOLETTO; AGUSTINI, 2009, p. 374).

$O$ retrato que se tem nesse primeiro recorte do filme, portanto, é o da vitória do discurso autoritário pedagógico sobre a polissemia, que é contida na medida em que o professor (de modo consciente ou não) antecipa-se ideologicamente como repressor ao colocar os alunos na posição de Anne Frank e encontra pouco interesse da classe na redação do autorretrato, muito embora 
o sujeito-aluno resista ao discurso de autoridade por meio de refúgios, como as conversas paralelas no fundo da classe. Essa movência de formações discursivas acontece; há um conflito na medida em que os alunos ou ignoram o professor, ou recusam-se a ocupar o lugar de autores, mas esse conflito de FD não faz com que o efeito-autor aconteça.

[...] no caso do Discurso pedagógico, o sujeito pode estar identificado com diferentes formações discursivas, como por exemplo, aquela materializada na posição sujeito-aluno, ou na posição sujeito-professor etc. Mas nem sempre haverá um confronto de formações que resulte em uma dominante outra, que caracterize uma nova ordem discursiva (GALLO, 2001, p. 2).

Ao passar para o segundo recorte analisado, dos 48 aos 53 minutos de projeção, quando os alunos leem os autorretratos, o tom do filme é outro, a argumentação e a autoria se fazem presentes. No começo do recorte, uma das alunas, Esmeralda (interpretada por Esmeralda Ouertani) lê sua redação, na qual se imagina como uma policial no futuro. Importante frisar as condições de produção (em sentido estrito) nas quais o filme e sua narrativa se inscrevem, a saber, uma escola pública da periferia de Paris, toda com alunos pobres, muitos dos quais imigrantes ou filhos de imigrantes (sobretudo africanos), no contexto político do então presidente Nicolas Sarkozy, governante de centro-direita, cuja gestão foi marcada pela xenofobia. Esses elementos denunciam o papel de fôrma-leitor no qual Esmeralda discursiviza(-se): “[...] realizando uma leitura parafrástica, 'pré-formatada', na qual os sentidos já estão dados e definidos" (IAMAMOTO; PACÍFICO, 2010, p. 197).

Ao se colocar representativamente como alguém que quer ser policial, a aluna, a priori, antecipa-se no lugar de seus opressores. Em nenhum momento desse relato ela sofre censura do professor, até que passa a descrever também seu apreço por gêneros musicais ligados à cultura da periferia parisiense (o rap, sobretudo) e termina com uma colocação que inclui gíria: "gosto de comer, dormir e andar pelo 'gueto" (Figura 3). É, então, que ela, finalmente, é interpelada pelo professor, que a obriga a dizer "bairro" no lugar de "gueto", vetando um dos pontos nos quais a garota não se identificava com o discurso de apoio à formação discursiva dominante, o que inclui ser policial. Dessa maneira, o professor silencia a assunção da autoria pela inscrição de significantes que, via esquecimento $\mathrm{n}^{\circ} 2$, surgem aos sujeitos-alunos como evidentes.

Os estudos de Pacífico (2016) e Iamamoto e Pacífico (2010) têm apontado que os sujeitos-alunos encontram brechas para resistir à interdição que o discurso pedagógico impõe aos discursos estranhos àqueles permitidos pela instituição escolar, especialmente, no tocante à argumentação, tal qual se pode constatar por algumas análises de redações produzidas por sujeitos-escolares, cujos sentidos de resistência dialogam com algumas cenas do filme analisado. 
Importante destacar que, já que a argumentação oral do aluno não foi considerada, ele posicionou-se, por escrito, contrário ao fato de ter de fazer uma atividade que não considerava interessante e o fez por meio de uma estratégia argumentativa que fingia atender às exigências da professora, usando mecanismos linguísticos característicos dos contos de fadas, como "Era uma vez" e a construção de um mundo imaginário que essa formulação constrói. No entanto, o aluno desconstruiu o discurso de "final feliz" ao produzir uma nova versão dos contos de fadas, em que fadas, bruxas, príncipes e princesas deram lugar a elementos mais próximos da sua realidade escolar, marcada pela letra feia, punição, reprovação (IAMAMOTO; PACÍFICO, 2010, p. 200).

Figura 3 - A voz do "gueto" deve ser a voz do "bairro"

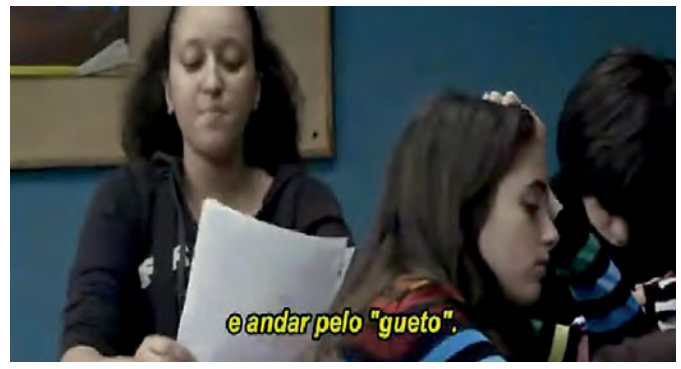

Fonte: Entre os muros da escola (2008).

Em seguida, um aluno chinês (vivido por Wei Huang) lê seu autorretrato, limitando-se a descrever as horas que passa jogando videogame e as alergias que tem. Não há, na redação do aluno, nenhuma menção sequer de confronto, problematização ou crítica à formação discursiva dominante representada pelo sujeito-professor. Morin parabeniza o aluno pelo trabalho, censurando, novamente, a aluna da redação anterior, que começava a instaurar um conflito com o garoto chinês, alegando que ele tem "alergia a si mesmo". Entre os muros da escola antecipa, neste momento, a revolta do sujeito-aluno que toma conta do restante do filme. Uma vez que se considera "aluno" como posição-sujeito e não como indivíduos, não se separa Esmeralda de Wei, entendendo assim a provocação de Esmeralda como o início de uma movência do sujeito-aluno em relação a si. A “alergia de si mesmo" é a repulsa pela repetição acrítica do discurso dominante que se materializa na redação de Wei, que converge perfeitamente com o que o professor gostaria de ouvir ou, nas palavras de Romão e Pacífico:

[...] argumentos clonados em série, as mesmas respostas, exercícios que se repetem com espaços de preencher lacunas e/ou testes e/ou perguntas dirigidas indicam que o pântano enganoso da repetição se instala (2006, p. 21).

Figura 4 - Sujeito-aluno se recusa a argumentar pela escrita

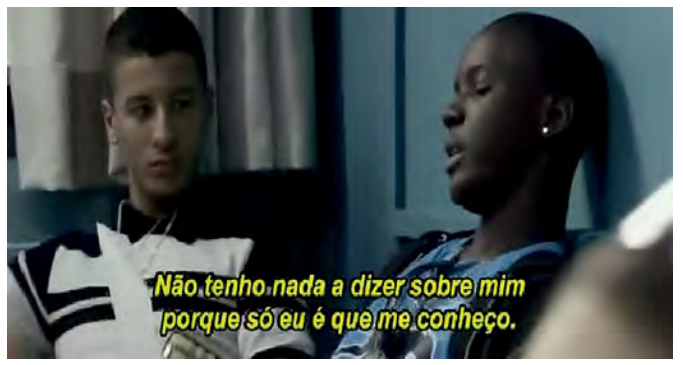

Fonte: Entre os muros da escola (2008).

Nos minutos seguintes, o professor solicita que outro aluno, Souleymane (Franck Keïta), leia sua redação. Chistoso, o jovem desde o começo desafia o 
professor, alegando que não escreveu nada. Morin segue um posicionamento linha dura desde o início da interlocução e o força, novamente, a ler o autorretrato. O aluno, enfim, cede e lê: "Me chamo Souleymane. Não tenho nada a dizer sobre mim porque só eu é que me conheço" (Figura 4), e é aplaudido pelos companheiros de sala. Cada vez mais irritado, Morin o confronta, ordenando que "se esforce como os outros". Souleymane continua firme na contestação ao professor e alega que não quer falar da própria vida como os demais. Mais uma vez, Esmeralda provoca: "ele não sabe escrever, é isso". O filme versa aqui, novamente, sobre o imaginário do sujeito-aluno acerca do verbal e da apreensão das normas gramaticais da norma culta da língua como condição sine qua non para a assunção da autoria. Ora, todo esse segundo recorte analisado parece desconstruir justamente esse imaginário, tão compartilhado por alunos e professores. A própria Esmeralda inscreveu um efeito de autoria, quando registrou uma marca de oralidade que foge ao padrão da norma culta escrita. Souleymane, se não se assumiu como autor, no mínimo, mostrou-se capaz de argumentar pelo silêncio, que aqui é abertamente político, uma recusa à submissão que a memória da escrita no AIE escolar representa; pouco tempo depois do recorte destacado (na altura de 1 hora e 5 minutos de filme), a assunção à autoria se dá justamente por meio do discurso imagético, no mural de fotos tiradas por
Souleymane, exposto, por iniciativa do sujeito-professor, para o resto da classe como um autorretrato (Figura 5).

Figura 5 - Sujeito-aluno e assunção da autoria fora do verbal

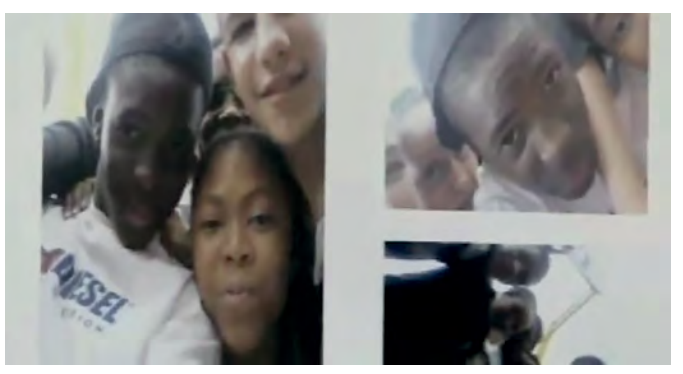

Fonte: Entre os muros da escola (2008).

Pacífico (2016), ao analisar como se dá a argumentação de sujeitos-alunos que frequentam o ensino fundamental, destaca que:

[...] os sujeitos-alunos defendem o direito à argumentação e reconhecem sua presença no cotidiano, nas práticas sociais, "porque o argumentar deve estar em nossas vidas". Apesar de a escola não fomentar práticas de argumentação, os sujeitos que frequentam essa instituição as defendem, o que vai em direção oposta ao discurso pedagógico do tipo autoritário (PACÍFICO, 2016, p. 204).

Este trecho vem ao encontro da linha argumentativa que sustenta esta análise, uma vez que, nesse instante do filme, a relação entre Morin e Souleymane chega a uma breve harmonia, que, ironicamente, representa uma vitória do sujeito-aluno que escapa ao discurso dominante, demonstrado por uma materialidade dominante (a escrita), e inscreve(-se) no efeito-autor, porém, sem abrir mão desse lugar de resistência. 
Essa "nova" posição-sujeito compreende o efeito-autor conceitualizado por Gallo (2001), ou seja, o confronto de FD se deu de fato no âmbito da autoria, do polêmico, num discurso - o pedagógico - tão institucionalizado como autoritário.

\section{Considerações finais}

Constata-se que, ao mobilizar o referencial teórico-metodológico da $\mathrm{AD}$ pecheutiana, foi possível investigar a autoria e a argumentação no espaço escolar, mesmo que a partir de um longa-metragem, ou melhor, por meio de um discurso artístico. A representação da escola e de seus sujeitos no filme escolhido apresenta efeitos de sentidos não só sobre autoria e argumentação, mas também sobre disciplina e confronto de sujeitos-alunos com o sujeito-professor que presenciamos no real. Percebe-se também que a argumentação na prática escolar recorre a outras materialidades que não somente a da escrita, como ao verbal (oralidade) e ao não verbal, que representam lugares de contestação à memória atrelada exclusivamente àquela.

A noção de sujeito ainda se fez essencial nesta análise, uma vez que, assim como Orlandi, se olhou para um sujeito que está imerso "no social que o envolve, e preso, pois, da contradição que o constitui" (2003, p. 33), o que levou a refletir sobre ideologia. Fora isso, a relevância desse tema é sustentada ao buscar, em Althusser (1980), compreender a escola como AIE. Se os AIEs são operadores da reprodução das relações de produção, também são os mesmos aparelhos que operam a transformação. Em termos da $\mathrm{AD}$, equivale a dizer que a paráfrase, a repetição, a tentativa de conter a polissemia e a sedimentação de um já-lá institucionalizado pelos AIEs - no caso do imaginário aqui analisado, o da escola - sempre encontrarão a resistência, a falha, o equívoco, a ruptura na/da qual emerge o acontecimento discursivo. Língua e equívoco estão, portanto, numa relação mutuamente constitutiva na estrutura da língua - e não apenas dela, como também quando o personagem do filme recorre ao imagético para fazer falar um gesto de autoria.

\section{The controversial space of} argumentation inscribed in the film Within the Walls

\begin{abstract}
In this work, we seek to understand the imagery about argumentation and authorship in the school institution as it is inscribed in meaning effects in Laurent Cantet's film Within the Walls (2008), based on the theoretical assumptions of the Discourse Analysis (AD) pecheutian matrix. Through the specific concepts of $\mathrm{AD}$ for the analysis of verbal and non-verbal discursive processes according to their respective materialities, but above all of the concepts of argumentation and authorship as also dealt with specifically by the theoretical framework of $\mathrm{AD}$, it was mobilized clippings from the film that evidence the school as an ideological apparatus of state
\end{abstract}


based on an authoritarian discourse, but also, a space in which the new can break up, the rupture with the already-there, the discursive event, the opening for the controversial discourse as described by Orlandi (2003).

Keywords: Argumentation. Authorship. Discourse. Imaginary. Movie theater.

\section{Referências}

ALTHUSSER, Louis. Aparelhos ideológicos de Estado. In: . Posições 2. Rio de Janeiro: Graal, 1980. (Biblioteca de Ciências Sociais, 17). p. 41-52.

BÉGAUDEAU, François. Entre les Murs. França: Folio France, 2003.

CORRÊA, Anderson Rodrigues. Entre os muros e não muros da escola. In: FAZENDO GÊNERO, 9, 2010. Florianópolis. Anais... Florianópolis, 2010. p. 1-8. Disponível em: <http://www.fazendogenero.ufsc.br/9/resources/anais/1277924212_ARQUIVO_TextoEntreosMuros.doc.pdf $>$. Acesso em: 15 set. 2017.

ENTRE OS MUROS da escola. Direção de Laurent Cantet. França, 2008. Disponível em: <https:/www.youtube.com/watch?v=rBXIPg7nj-Y>. Acesso em: 10 maio 2017.

FERREIRA, Maria Cristina Leandro. Nas trilhas do discurso: a proposta de leitura, sentido e interpretação. In: ORLANDI, Eni Puccinelli (Org.). A leitura e os leitores. 2. ed. Campinas: Pontes, 2003. p. 201-208.

FOUCAULT, Michel. Vigiar e punir: nascimento da prisão. Tradução de Raquel Ramalhete. 20. ed. Petrópolis: Vozes, 1987. Disponível em: <https://edisciplinas.usp.br/ pluginfile.php/121335/mod_resource/content/1/Foucault_Vigiar\%20e\%20punir $\% 20$ I\%20e\%20II.pdf>. Acesso em: 10 jul. 2017.
FRANK, Anne. O Diário de Anne Frank. Países Baixos: Contact Publushing, 1974.

GALLO, Solange Leda. Autoria: questão enunciativa ou discursiva? Linguagem em (Dis)curso, Tubarão, v. 1, n. 2, p. 01-03, jun. 2001. Disponível em: <http://www.portaldeperiodicos.unisul.br/index.php/Linguagem_Discurso/article/view/172/186>. Acesso em: 20 ago. 2017.

GRIGOLETTO, Evandra; AGUSTINI, Carmen. A autoria na escrita de adolescentes: interfaces entre o virtual e o escolar. In: INDURSKY, Freda; FERREIRA, Maria Cristina Leandro; MITTMANN, Solange (Org.) $O$ discurso na contemporaneidade: materialidades e fronteiras. São Carlos: Claraluz, 2009. p. 369-380. Disponível em: <https://issuu. com/prazeremler/docs/contemporaneidade>. Acesso em: 10 set. 2017.

IAMAMOTO, E. N.; PACÍFICO, S. M. R. Sujeito e sentido nas produções textuais das séries iniciais do Ensino Fundamental: "o que quer, o que pode essa escrita?”. In: ROMẪO, L. M. S.; PACÍFICO, S. M. R. (Org.). Efeitos de leitura: sujeitos e sentidos em movimento. Ribeirão Preto: Alphabeto, 2010. p. 181-207.

MUSSALIM, Fernanda. A análise do discurso. In: MUSSALIM, Fernanda; BENTES, Anna Christina (Org.). Introdução à lingüistica: domínios e fronteiras. São Paulo: Cortez, 2000. cap. 4. p. 101-142. Disponível em: <http://www.fernandamussalim.com.br/ wp-content/uploads/2015/01/capitulo_analise_do_discurso.pdf $>$. Acesso em: 30 jul. 2017.

NECKEL, Nádia Régia Maffi. Do Discurso Artístico à percepção de diferentes processos discursivos. $128 \mathrm{f}$. Dissertação (Mestrado em Ciências da Linguagem) - Universidade do Sul de Santa Catarina, Florianópolis, 2004. Disponível em: <http://pergamum.unisul.br/ pergamum/pdf/73810_Nadia.pdf $>$. Acesso em: 03 ago. 2017.

ORLANDI, Eni de Lourdes Puccinelli. Segmentar ou recortar? In: GUIMARÃES, Eduardo (Org.) Linguística: questões e controvérsias. Uberaba: Fiube, 1984. (Sé- 
rie Estudos, 10). p. 09-26. Disponível em: $<$ https://documents.mx/documents/orlandi-segmentar-ou-recortar.html>. Acesso em: 29 jul. 2017.

Efeitos do verbal sobre o não-verbal. Rua, Campinas, n. 1, p. 35-57, 1995. Disponível em: <https://periodicos.sbu.unicamp.br/ojs/ index.php/rua/article/view/8638914/6517>. Acesso em: 22 ago. 2017.

. Análise de Discurso: princípios e procedimentos. Campinas: Pontes, 1999.

A linguagem e seu funcionamento: as formas do discurso. 4. ed. Campinas: Pontes, 2003.

OS INCOMPREENDIDOS. Direção: François Truffaut. França, 1959.

PACÍFICO, S. M. R. O direito à argumentação no contexto escolar. In: PIRIS, E. L.; FERREIRA, M. O. (Org.). Discurso e Argumentação em múltiplos enfoques. Coimbra: Grácio Editor, 2016. p. 191-212.

PÊCHEUX, Michel. O Discurso: estrutura ou acontecimento. Tradução de Eni P. Orlandi. Campinas: Pontes, 1999a.

. Semântica e discurso: uma crítica à afirmação do óbvio. Campinas: Unicamp, 1969.

. Semântica e discurso: uma crítica à afirmação do óbvio. Tradução de Eni P. Orlandi et al. 5. ed. Campinas: Unicamp, 2014.

Papel da memória. In: ACHARD, Pierre et al. Papel da Memória. Campinas: Pontes, 1999b. p. 49-57.

ROMÃO, Lucília Maria Sousa; PACÍFICO, Soraya Maria Romano. Era uma vez outra história: leitura e interpretação na sala de aula. São Paulo: DCL, 2006.

SE... Direção: Lindsay Anderson. Reino Unido, 1968.

SOUSA, Lucília Maria Abrahão; GARCIA, Dantielli Assumpção. "Ideias são à prova de bala": a voz dos secundaristas em discurso. In: MASSMANN, Débora Raquel Hettwer;
ANDRADE, Guilherme Beraldo; SOUSA, Tatiana Barbosa (Org.). Linguagem, sentido e sociedade. Campinas: Pontes, 2017. p. 13-29.

SOUZA, Tania Conceição Clemente. Discurso e cinema: uma análise de Limite. Ciberlegenda, Niterói, RJ, n. 4, p. 01-19, 2001. Disponível em: <http://www.ciberlegenda.uff.br/ index.php/revista/article/viewFile/356/236>. Acesso em: 08 ago. 2017.

Discurso e imagem: perspectivas de análise do não verbal. Ciberlegenda, Niterói, RJ, n. 1, p. 01-10, 1998. Disponível em: <http://www.ciberlegenda.uff.br/index. $\mathrm{php} / \mathrm{revista} / \mathrm{article} / \mathrm{view} / 240 / 128>$. Acesso em: 12 ago. 2017. 